\title{
Geometric morphometric analysis as a proxy to evaluate age-related change in molar shape variation of low-crowned Notoungulata (Mammalia)
}

\author{
Alejo C. Scarano1,2,3 (i) | Bárbara Vera4
}

${ }^{1}$ División Paleontología de Vertebrados, Museo de La Plata, Paseo del Bosque s/n. B1900FWA La, Plata, Argentina

${ }^{2}$ Consejo Nacional de Investigaciones Científicas y Técnicas (CONICET), Godoy Cruz 2290 (C1425FQB) CABA, Argentina

${ }^{3}$ Universidad Nacional de Avellaneda (UNDAV), España 350, Avellaneda, Buenos Aires, Argentina

${ }^{4}$ Instituto Argentino de Nivología, Glaciología y Ciencias Ambientales (IANIGLA), CONICET, Avenida Ruiz Leal s/n, Mendoza 5500, Argentina

\section{Correspondence}

Alejo C. Scarano, División Paleontología de Vertebrados, Museo de La Plata, Paseo del Bosque s/n. B1900FWA La, Plata, Argentina.

Email: scarano@fcnym.unlp.edu.ar

\section{Funding information}

Consejo Nacional de Investigaciones Científicas y Técnicas (CONICET, Argentina); Field Museum of Natural History, USA (to B.V.), Grant/Award Number: 2010-P305326; Williams Foundation travel grant (2011); University of Padova, Italy (via "Proposte di finanziamento per azioni di cooperazione universitaria," 2011 and 2014); PICTO-UNDAV 105, Préstamo BID

\begin{abstract}
Shape and age variation in dentition of Paleogene extinct native South American ungulates (Notoungulata) has been traditionally described using qualitative and quantitative approaches, and has played a controversial role in the systematics of several groups. Such is the case of the Notopithecidae, a group of notoungulates with low-crowned teeth, known from the middle Eocene of Patagonia (Argentina). In this group, as well as in other contemporary families, extreme morphological changes associated to increasing dental wear were originally assumed to represent taxonomic differences; thus, dozens of species were erected, clearly reflecting the difficulty of defining discrete characters. In this contribution, a total of 89 upper molars and 91 lower molars were analyzed distributed in two factors, wear and species; three species of notopithecids were considered as study case, Notopithecus adapinus, Antepithecus brachystephanus, and Transpithecus obtentus, based on the large and well-identified sample of upper and lower molars for each species. We have coupled geometric morphometric analyses with traditional comparative methods to get a better understanding and interpretation of both the changes in tooth shape contour and the link between shape and ontogeny. In addition, we evaluate the utility of this approach to identify which changes are strictly wear-related and also test the qualitative characteristics used for diagnosing and differentiating notopithecid species. Our study yielded consistent results when applying independent geometric morphometric analyses on complex structures such as brachydont molar teeth. The landmark data is highly congruent with alternative sources of evidence, such as morphological studies using discrete characters. In notopithecid species, wear is the main factor affecting molar shape, followed by species (in lower molars) and allometry; in addition, lower teeth morphology is more definitive in separating species than upper molars, a fact that entails a key point for systematic studies of Paleogene brachydont notoungulates.
\end{abstract}

\section{KEYWORDS}

brachydont, cheek teeth, middle, Eocene, wear

\section{1 | INTRODUCTION}

Wear is widely known to modify the shape, affect the function, and compromise the structural integrity of the dentition of herbivorous mammals throughout ontogeny (Butler, 1983; Fortelius \& Solounias, 2000; Lucas, Constantino, Wood, \& Lawn, 2008; M'kirera \& Ungar, 2003; Rensberger, 1973; Ungar, 2015). Much of this debate has focused on the study of what causes mammalian tooth wear, especially that of herbivores (Damuth \& Janis, 2011; Fox, Juan, \& Albert, 1996; Janis \& Fortelius, 1988; Lucas et al., 2014); however, a general consensus regarding the mechanics of tooth wear and its causes (e.g., the historical dichotomy of phytoliths versus exogenous grit) has not yet been reached (Erickson, 2014; Fortelius, 1985; Fox et al., 1996; Janis, 1995; Kubo \& Yamada, 2014; MacFadden, 1997; Massey \& Hartley, 2006; Sanson, Kerr, \& Gross, 2007; Simpson, 1953; Stromberg, 2006). While the way that tooth shape changes with wear may have a genetic 
underpinning, tooth wear itself is not inherited; in this sense, the patterns of wear of fossil teeth reflect real behaviors of specific individuals during their lifetime (Ungar, 2009).

Traits associated with tooth shape, such as upper molars with rectangular, squared, or trapezoidal outlines, have been traditionally used as discrete and qualitative characters in systematic and phylogenetic analyses to separate species and genera of notoungulate groups; however, tooth shape is a continuum rather than a discrete character because it is controlled by wear. Geometric morphometrics (GM) is an approach used to quantify differences in morphological shape, including statistical differences between individuals, sexes, or species, as well as transformational modifications between ontogenetic stages, between stratigraphic units, or along branches of a phylogenetic tree (Polly et al., 2016 and references therein). Moreover, geometric morphometrics is favored over traditional morphometric methods (e.g., Claude, 2013) because it allows capturing the geometry of morphological structures, preserving this information throughout the analyses (Adams, Rohlf, \& Slice, 2004). Bernal (2007) compared traditional versus GM techniques on a study of size and shape of human molars, demonstrating that a considerable amount of information about molar contour and some morphological features can accurately be captured by means of GM methods and, in addition, that differences among samples were only found by means of GM analyses. Catalano, Ercoli, and Prevosti (2014) established that landmark configurations can be an important source of evidence for phylogenetic analysis in mustelids, with their results being congruent with the relationships defined for the group based on molecular and discrete morphological characters.

Traditionally, shape and age variation in the dentition of extinct native South America ungulates (Notoungulata) has been described in terms of both qualitative (morphological) and quantitative (linear dimensions or other measurements) changes, taking a controversial role in the systematics of several groups (e.g., Billet, De Muizon, \& Quispe, 2008; Billet et al., 2009; Cerdeño, Montalvo, \& Sostillo, 2017; Cerdeño, Reguero, \& Vera, 2010; Cerdeño et al., 2008; Croft, Reguero, Bond, Wyss, \& Flynn, 2003; Francis, 2013; Madden, 1997; Vera, 2012a,2017). For instance, using geometric morphometrics to analyze high-crowned upper and lower teeth, Ercoli, Candela, Rasia, and Ramírez (2017) revalidated a species of Paedotherium (Hegetotheriidae) from the Late Miocene; however, no previous GM analysis has been done on the low-crowned dentition of Eocene notoungulates.

In particular for notoungulates with low-crowned teeth, ontogenetic sequences based on extreme morphological changes associated to increasing wear on dentition were originally assumed to represent taxonomic differences and dozens of species were erected, a fact that clearly highlighted the difficulty of defining discrete characters. Such is the case for notopithecids (Ameghino, 1897, 1901, 1903, 1904).

Notopithecids are a group of small-sized notoungulates, characterized by having cheek teeth with low crowns and closed roots (= brachydont, Mones, 1982). The group was particularly diverse during the Casamayoran SALMA (South America Land Mammal Age; middle-late Eocene) of Patagonia (Argentina). As is common for other small and poorly known groups of Eocene mammals from South America with similar dental morphology (e.g., archaeopithecids, oldfieldthomasiids), notopithecids are primarily recorded by fragmentary dental remains or isolated cheek teeth, which have been the basis for the characterization of most of these groups. In fact, notopithecid diversity has been overestimated based on morphological and metrical differences (Ameghino, 1897, 1901, 1903, 1906; Simpson, 1945, 1967). Indeed, Ameghino (1906) recognized eight genera and 20 species within the Notopithecidae, considering only upper dentition, whereas Simpson (1967) proposed a total of four genera and seven species for this group.

More recently, an exhaustive study of this group concluded that the main morphological variations among the different species originally erected within Notopithecidae are due to degrees of wear and intraspecific variation, instead of interspecific variation (Vera, 2012a, 2013, 2016; Vera \& Cerdeño, 2014). In addition, a new phylogenetic hypothesis was proposed for this group, considering it as a clade comprising four monospecific genera, Notopithecus adapinus Ameghino 1897, Antepithecus brachystephanus Ameghino 1901, Transpithecus obtentus Ameghino 1901, and Guilielmoscottia plicifera Ameghino 1901 (Vera, 2016).

In this context, and considering the unusually large sample available for this group, notopithecids represent as a good case-study to assess age-related molar shape variation, using for the first time a GMbased approach for low-crowned notoungulates.

In this contribution, we combine GM with traditional comparative methods to achieve a better understanding and interpretation of both the changes in tooth shape contour and the link between shape and ontogeny (degree of wear). In addition, we evaluate the utility of this approach to distinguish changes that are strictly wearrelated from those qualitative characteristics used for diagnosing and differentiating notopithecid species. The goal of this study is to provide a useful proxy for the better understanding of other still little known South American Paleogene brachydont groups with similar characteristics.

\section{1 | Repositories and institutional abbreviations}

American Museum of Natural History, Fossil Mammals (AMNH FM), New York, USA; Field Museum of Natural History, Chicago (FMNH), Chicago, USA; Museo Argentino de Ciencias Naturales "Bernardino Rivadavia," Ameghino and Paleovertebrata collections (MACN-A/Pv), Buenos Aires, Argentina; Museo di Geologia e Paleontologia (MGP), Università degli Studi di Padova, Italy; Museo de La Plata (MLP), La Plata, Argentina; Muséum national d'Histoire naturelle, Casamayoran collection (MNHN-CAS), Paris, France; Museo Paleontológico "Egidio Feruglio," Vertebrate Paleontology collection (MPEF-PV), Trelew, Argentina.

\section{2 | Other abbreviations}

M1, M2, M3: first, second, and third upper molars; m1-m2, first and second lower molars; WS, wear stage. 


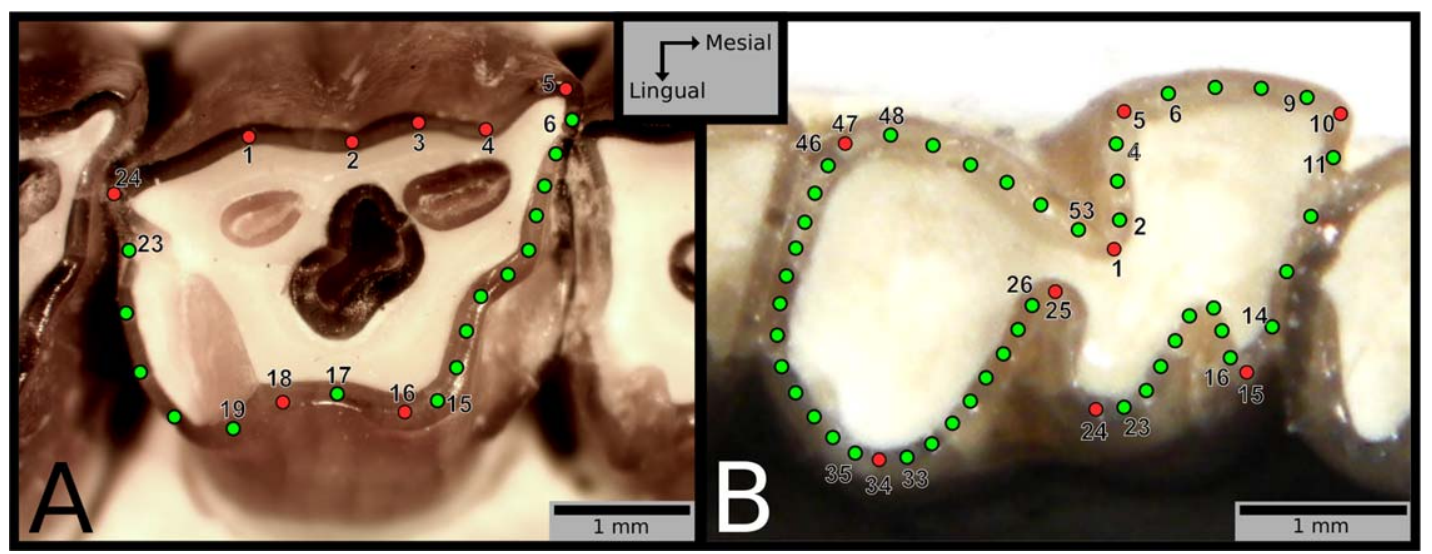

FIGURE 1 (a) moderate worn upper molar and (b) moderate worn lower molar showing landmarks (red) and semilandmarks (green) placement

\section{2 | MATERIAL AND METHODS}

\section{1 | Data sources}

The specimens included in the present study were taken from Vera's database (2013) which represents the largest and most complete sample recognized for Notopithecidae species. The examined specimens are deposited in the collections of several institutions: $\mathrm{AMNH}, \mathrm{FMNH}$, MACN, MGP, MLP, MNHN, and MPEF.

On the basis of the number of preserved teeth for each taxon, three species of Notopithecidae were selected, namely Notopithecus adapinus, Antepithecus brachystephanus, and Transpithecus obtentus (Supporting Information Appendix 1); conversely, Guilielmoscottia plicifera was not included in this study due to its small number of known specimens.

Tooth shape morphology of notopithecids was explored through the analysis of photographs of upper (M1, M2, and M3) and lower molars ( $\mathrm{m} 1$ and $\mathrm{m} 2$ ) because these teeth are numerically better represented in collections with respect to the less abundant premolars. It should be noted that $\mathrm{m} 3$ were excluded from the analysis due to their dissimilar morphology (e.g., extra lophids and cusps) with respect to $\mathrm{m} 1$ and $\mathrm{m} 2$. This morphological disparity between $\mathrm{m} 3$ and $\mathrm{m} 1-2$ may obscure other possible patterns in the shape data; it does not happen in upper molars, in which the morphology is more homogeneous, and therefore M3 was included in these analyses.

To standardize the photographs, each tooth was positioned as shown in Figure 1, including a ruler to account for size in the analyses. In addition, to maximize sample size, the left molar was photographed when the corresponding right molar was not preserved; left-side molars were flipped (reflected) before performing the analyses. Teeth with extreme attritional wear, broken parts and/or with uncertain location for one or more landmarks were not included in the study.

A total of 89 upper molars and 91 lower molars were analyzed and categorized in two factors, species and wear (Supporting Information Appendix 1). Although the sample sizes are not equal across the two factors levels, all are well represented. Upper and lower molars were treated separately.
Selected upper and lower molars were classified into three categories according to the degree of wear and each tooth was treated as an independent unit. These wear stages (WS) were defined based on general and particular morphological characteristics observed on molars throughout ontogeny for each species, with a classification of WS $=1$ for a little worn tooth, WS $=2$ for a moderately worn tooth, and WS= 3 for a very worn tooth (Table 1). Methodology and tooth terminology follow Vera (2012a, 2013, 2016, and references herein).

\section{2 | Geometric morphometric analyses}

Geometric morphometric methods were used to analyze the shape and size of the occlusal morphology of cheek teeth for the three notopithecid species, following several authors (Adams et al., 2004; Klingenberg 2016; McGuire 2010; Rohlf \& Marcus, 1993; Zelditch, Swiderski, \& Sheets, 2012). These methods quantify the shape of anatomical objects from the coordinates of homologous locations, after the effects of nonshape variation (i.e., orientation, position, and scale) are mathematically held constant (Adams, Rohlf, \& Slice, 2013; Kelly, Folinsbee, Adams, \& Jennions, 2013; Klingenberg, 2016).

For the upper molars, the two-dimensional coordinates of eight landmarks were digitized over the occlusal surface, and 16 equidistant semilandmarks (Gunz \& Mitteroecker, 2013) along the enamel outline of each tooth were included to capture its curvature (Figure 1a and Supporting Information Appendix 2). For the lower molars, a total of eight two-dimensional coordinate landmarks were digitized and 45 equidistant semilandmarks along the enamel outline of the teeth were included (Figure 1b and Supporting Information Appendix 2). The semilandmarks were slid using the minimal bending energy criterion (Bookstein, 1996, 1997; Bookstein, Streissguth, Sampson, Connor, \& Barr, 2002).

The landmark configurations were subjected to a Generalized Procrustes Analysis (Rohlf \& Slice, 1990), in which the configurations are scaled to a centroid size of one, transposed and rotated, so that the sum of squared distances between corresponding landmarks is minimal. After superimposition, the aligned shape coordinates were projected 


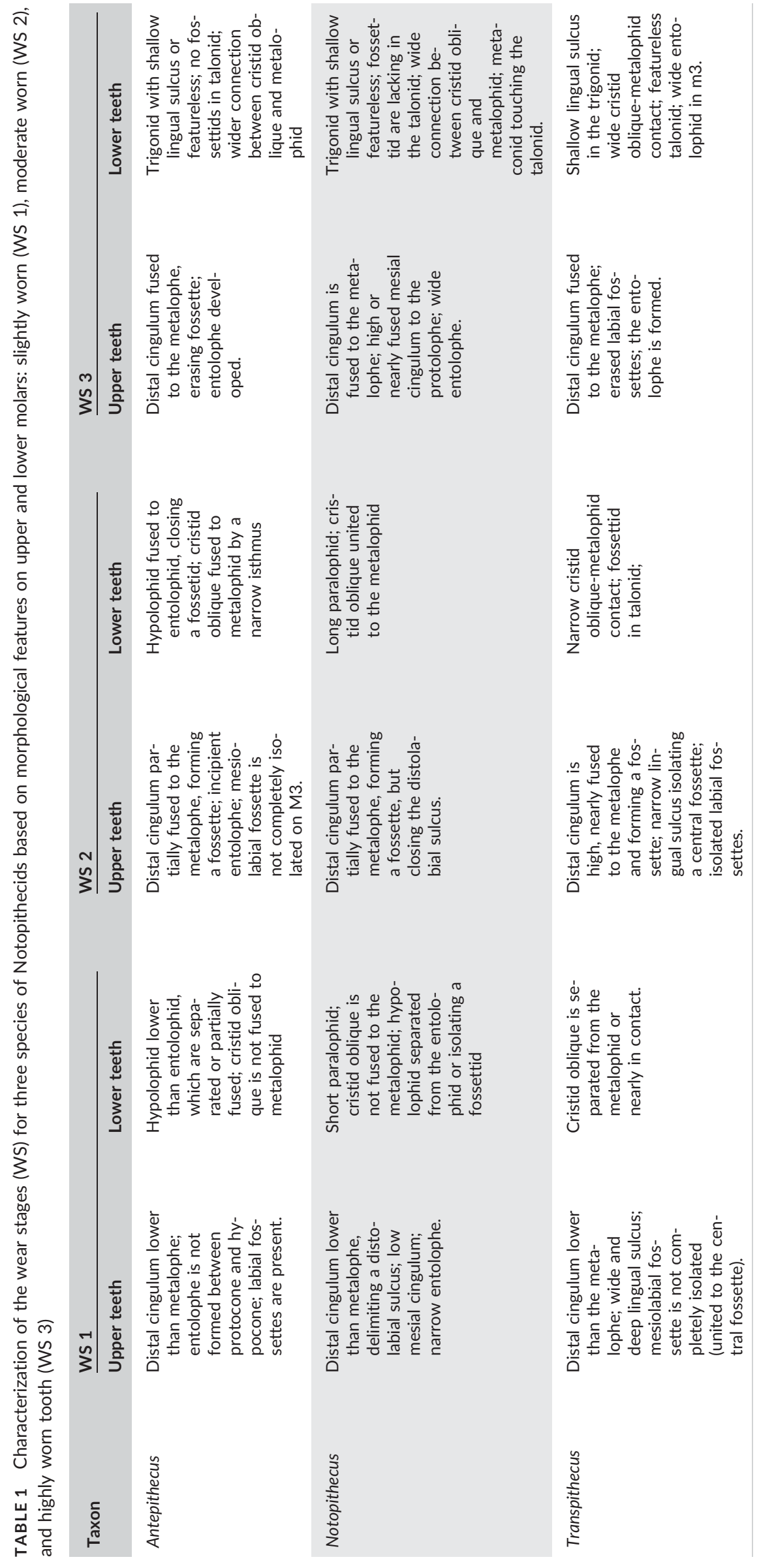




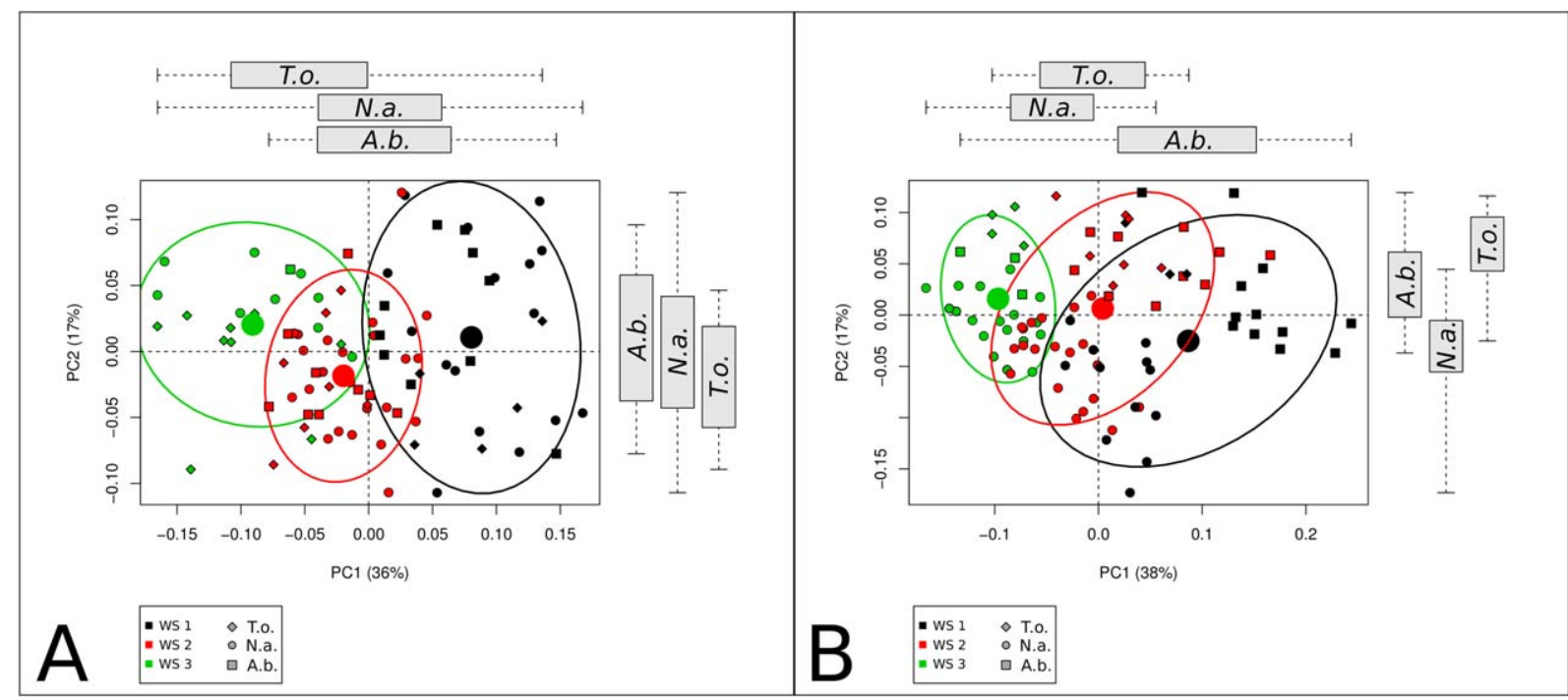

FIGURE 2 Plots of the first and second principal components (PC1 and PC2). (a) upper molars. (b) lower molars. Wear stages are showed in different colors with $80 \%$ ellipses for each stage. Big dots represent group centroids. WS 1, slightly worn tooth (black); WS 2 , moderate worn tooth (red); WS 3, highly worn tooth (green). Marginal boxplots represent the principal components scores distribution for each species in each component. The boxes represent the interquartile range and the lines (whiskers) extend to the extreme values (minimum and maximum). T.o., Transpithecus obtentus; N.a., Notopithecus adapinus; A.b. Antepithecus brachystephanus

orthogonally into a linear tangent space yielding Kendall's tangent space coordinates (Berns \& Adams, 2013; Claude, 2008; Dryden \& Mardia, 1998; Rohlf, 1999), which were treated as a set of shape variables to be used in the exploration of shape variation. In addition, centroid size (CS) was also retained for further analyses. The digitizing process was performed using TpsDig2 (Rohlf, 2008) and morphometric analyses were performed in R 3.0.2 (R Development Core Team, 2013), using routines in the package "geomorph" (Adams \& Otárola-Castillo, 2013).

\subsection{Analysis of the tangent space coordinates}

First, a principal components analysis (PCA) of the tangent space coordinates was performed to visualize the major trends of shape variation and possible patterns of distribution of specimens along each factor (wear and species). The plots of the first and second principal components (PC1 and PC2) show the two main axes of variation of the data, where the different wear stages are represented in different colors and $80 \%$ ellipses were plotted for each stage. The distribution of the species factor in the PCA plot is depicted by a series of marginal boxplots that represent the distribution of principal component scores for each species in each component. The boxes represent the interquartile range and the lines (whiskers) extend to the extreme values (minimum and maximum).

Second, a nonparametric MANOVA (np-MANOVA) with permutation was conducted (Anderson, 2001; Collyer, Sekora, \& Adams, 2015). This analysis quantifies the relative amount of shape variation attributable to the factors in a linear model, and estimates the probability of this variation by distributions generated from resampling permutations. A randomized residual permutation procedure (RRPP) was conducted to generate statistical distributions and effect sizes. The RRPP is a procedure that uses resampling to randomize the residual vectors of a matrix of residuals from a reduced model to calculate pseudorandom values for estimation of effects from a full model (Adams \& Collyer, 2007, 2009; Collyer \& Adams, 2007, 2013; Collyer, Stockwell, Adams, $\&$ Reiser, 2007; Collyer et al., 2015). The advantage of this permutation approach, compared with the traditional randomizing vectors of raw values, is that it holds constant the effects of the reduced model and is not constrained by the high-dimensionality of the data (Collyer et al., 2015). It also allows estimation of relative effect sizes as standard deviations of sampling distributions (see Adams \& Collyer, 2016; Collyer et al., 2015 for a detailed description of effect sizes and its estimation). Therefore, one of the most remarkable aspects of this methodology is that one can compare the effects size both within and among different studies (Collyer et al., 2015).

Finally, a regression of shape on size was conducted in order to describe the multivariate relationship between size and shape. The allometric pattern was visualized through a series of plots that describe the multivariate relationship between size and shape derived from landmark data. The abscissa of the plot represents size as log (CS), while the ordinate represents shape, calculated as the common allometric component of the shape data (CAC), which is in turn an estimate of the average allometric trend within groups (Mitteroecker, Gunz, Bernhard, Schaefer, \& Bookstein, 2004).

\section{3 | RESULTS}

\section{1 | Principal component analysis of the tangent space coordinates}

For the upper molars, the first two principal components explain 53\% of the total shape variation (Figure 2a; Supporting Information 


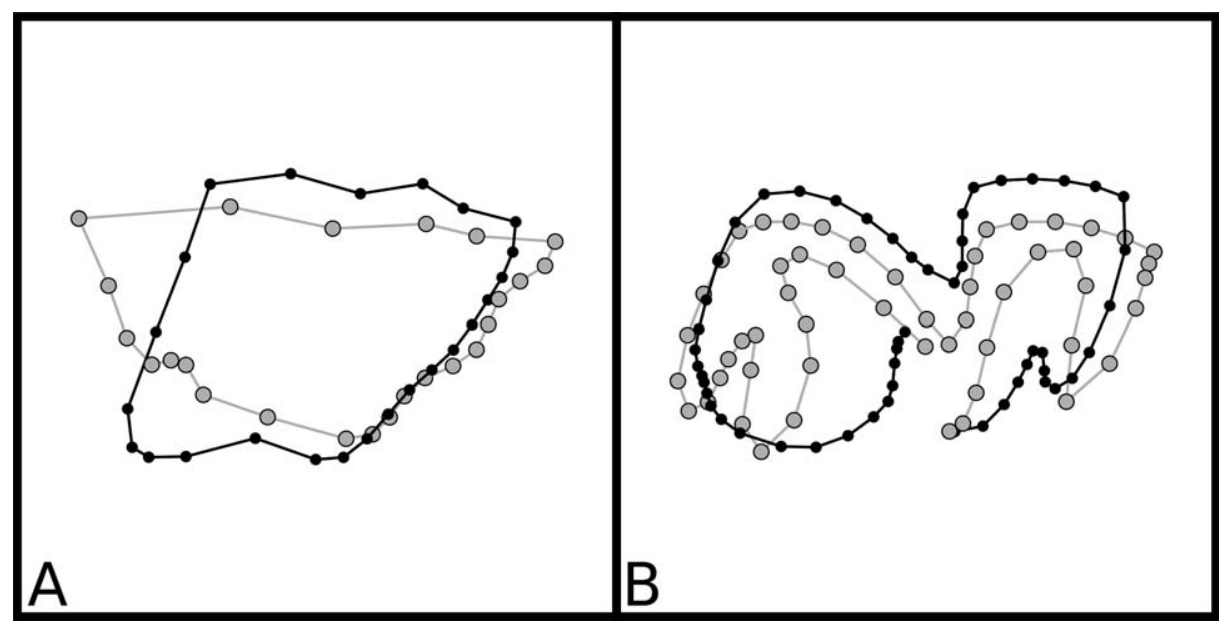

FIGURE 3 Comparison of the extreme shapes of the PC1, representing the major direction of shape change. (a) upper molar. (b) lower molar. Gray outline represents the positive PC1 extreme shape. Black outline represents the negative PC1 extreme shape

Appendices 3 and 4). The different wear stages are clearly identified mainly along the first principal component, with slightly (WS 1) and highly (WS 3) worn teeth located at the positive and negative extremes of PC1, respectively. The marginal boxplots show a high degree of overlapping among species in the first two principal components, mainly between Notopithecus and Antepithecus, while Transpithecus differentiates from them and shows negative values on PC1 (Figure 2a).

For the lower molars, the first two principal components explain $55 \%$ of the total shape variation (Figure $2 \mathrm{~b}$; Supporting Information Appendices 3 and 4). The different wear stages are clearly identified mainly along the first principal component with some degree of overlapping, and the slightly (WS 1) and highly (WS 3) worn teeth are located at the positive and negative values of PC1, respectively (Figure $2 b$ ), in concordance with the pattern described for upper molars (Figure 2a). However, the different species are better separated along both the first and the second principal components (Figure 2b), in contrast with the case of the upper dentition. Along PC1, Transpithecus and Notopithecus overlap moderately, whereas Antepithecus is clearly differentiated from them; in turn, the three species are also better separated along the second principal component (Figure 2b).

The major direction of shape change represented by PC1 is shown in Figures 3a,b. Regarding upper molars, two remarkable extremes can be observed, from slightly worn molars (WS 1, Table 1) which are characterized by being trapezoidal with narrow (labiolingually compressed) and long crowns (gray line in Figure 3a), to highly worn molars (WS 3, Table 1) which are characterized by having a square outline and wider and shorter crowns (black line in Figure 3a).

In turn, for lower molars, the major direction of shape change represented by PC1 (Figure 2b) is displayed in Figure 3b. Slightly worn lower molars (WS 1, Table 1) are characterized by having a long and narrow (labiolingually compressed) crown, a deep lingual valley in the trigonid, marked mesial and distal valleys in the talonid, a deep labial sulcus between trigonid and talonid, and well-differentiated lophids (gray line in Figure 3b). In the negative extreme of PC1, typical highly worn lower molars (WS 3, Table 1) are characterized by having shorter and wider crowns, a shallow lingual sulcus in the trigonid, less differentiated lophids, and a rounded talonid due to erased lingual valleys (black line in Figure 3b).

\section{2 | The np-MANOVA analyses}

The MANOVA analysis indicates that both factors, wear and species, were significant $(p<.05)$ for both upper and lower molars (Table 2). However, the interaction term wear $\times$ species was not significant for upper molars, whereas it was significant $(p<.05)$ for lower molars, indicating an interaction of factors on shape. It is important to remark that although both the main factors and the interaction term are statistically significant for lower molars, their effect sizes are different (Table 2). The $R^{2}$ and effect size ( $Z$ score) values obtained respectively for wear $(0.26 ; 11.6)$ and species $(0.14 ; 9.1)$ show that wear is the major factor that accounts for variation in the shape of lower molars (26\% approximately), followed by the factor species ( $14 \%$ approximately). In contrast, the interaction term wear $\times$ species accounts for only $5 \%$ of the shape variation with an effect size of $2.2 \mathrm{sd}$ (and a $p$ value $<.05$ ), indicating that small differences are statistically but not "biologically" significant. Moreover, these values are in concordance with the distribution and clustering observed in the principal component analysis (Figure $2 b$ ), in which the wide scattering of Antepithecus could be the source of such significant interaction.

\section{3 | Effect of size on molar shape}

The multivariate regression of shape on size (log CS) was significant ( $p$ value $<.05$ ) for both upper and lower molars, indicating a considerable amount of shape variation attributable to covariation with size (Table 2 , Figure 4a,b). Moreover, in upper molars, size (log CS) is the second most important factor accounting for shape variation, after wear (Table 2). The homogeneity of slopes test between size (log CS) and wear by species was not significant either in lower ( $p$ value 0.8851 ) or upper ( $p$ 
TABLE 2 Anova table (Type I, sequential, significance testing by RRPP 10,000 permutations) for upper and lower molars

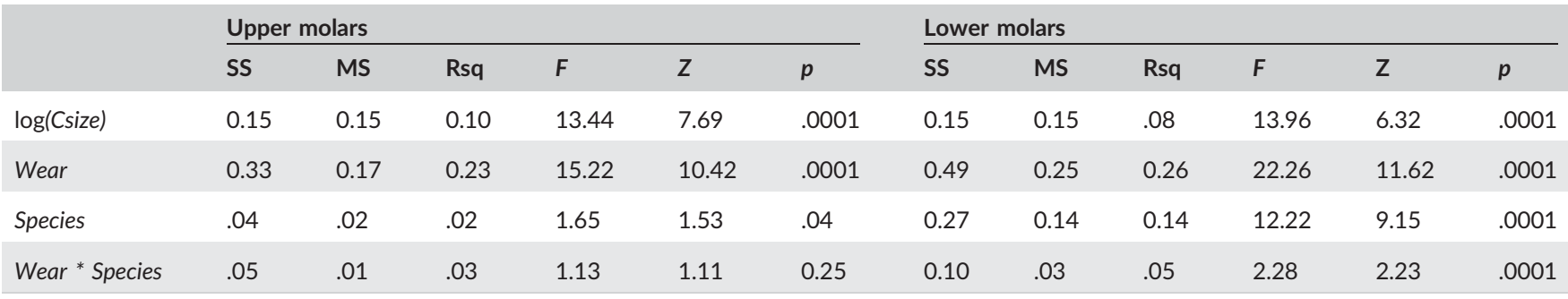

$\mathrm{SS}$, the sums of squares for each term; MS, the mean of squares for each term; Rsq, the coefficient of determination for each model term; $\mathrm{F}$, the $\mathrm{F}$ values for each model term; Z, the standard deviates or Z-scores; $p$, the $p$ values for each term from resampling permutations.

value 0.705$)$ molars, indicating a common shape-size allometry among groups.

\section{4 | Testing the importance of factors for species shape differences}

Because wear and covariation of size (CS) and shape are significant in both upper and lower molars (Table 2), two linear models were compared to assess shape differences between species after accounting for wear and size (the two main factors affecting shape in upper molars). One of them is a "reduced model" lacking the species factor (shape $~$ CS + wear) and the other one is a "full model" including the species factor (shape $\sim \mathrm{CS}+$ wear ${ }^{*}$ species). The pairwise comparisons between species show that shape differences in upper molars are not significant after accounting for size and wear (Table 3). This reinforces the notion that upper molar crown shape is mainly determined by wear and allometry. In the case of lower molars, the pairwise comparisons yielded significant differences in molar shape among the three species (Table 3). These results would indicate that after controlling for wear and size, there are still significant differences between the mean shapes of the three species involved.

\section{4 | DISCUSSION}

Recent contributions regarding notopithecids have greatly improved the knowledge for three of their representatives, namely Notopithecus adapinus, Antepithecus brachystephanus, and Transpithecus obtentus, by integrating morphological characters of both upper and lower dentition, and considering in some cases features of the skull and postcranial bones as well (Vera, 2012a,b, 2013, 2016; Vera \& Cerdeño, 2014). Indeed, one of the most important systematic advancements, made using a classic qualitative approach, was the idea that the number of originally described species, especially for Notopithecus and Antepithecus, had been overestimated. This overestimation was explained by considering that the variation observed among specimens is due to wear occurring during ontogeny instead of interspecific differences (Vera, 2013, 2016).
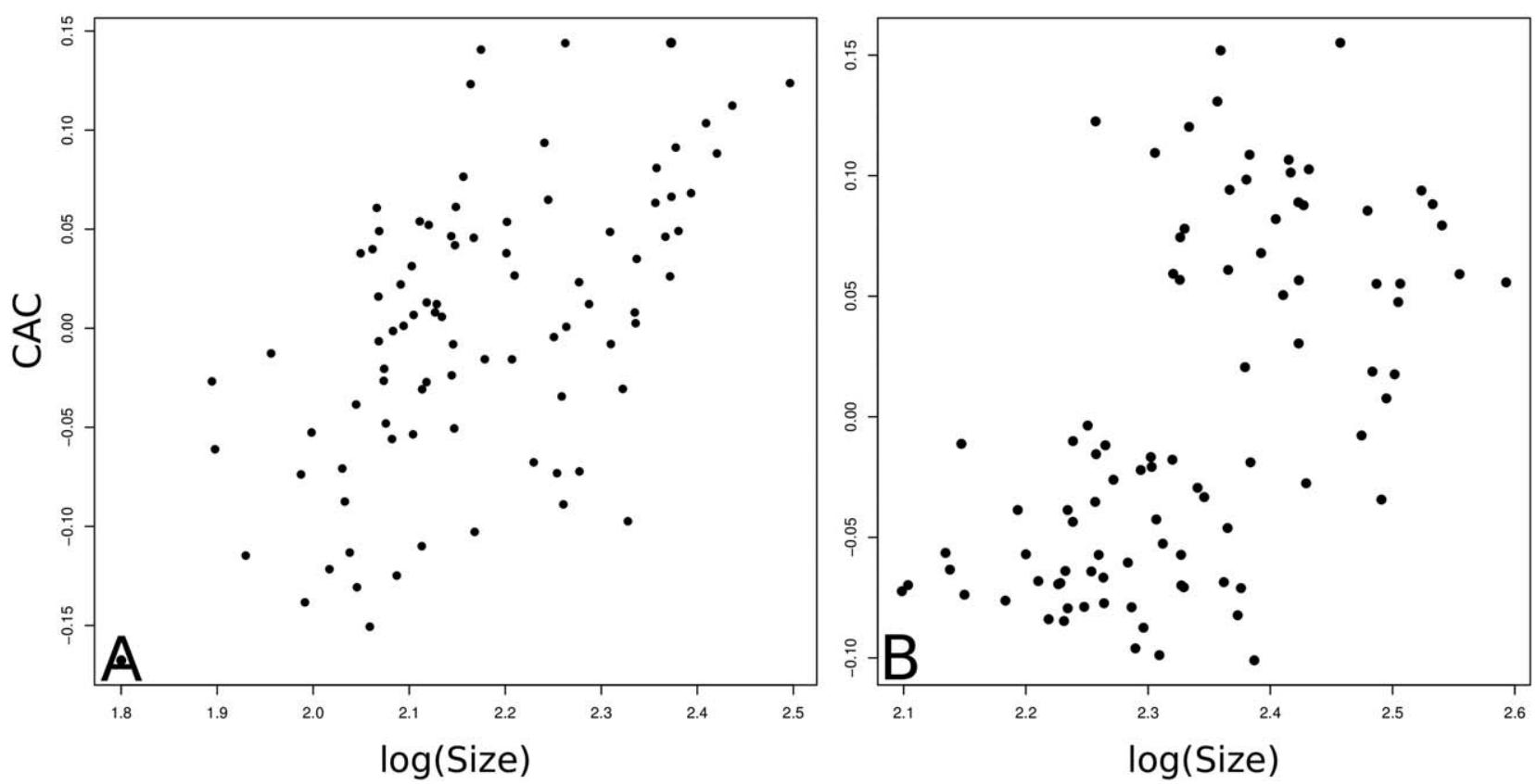

FIGURE 4 Scatterplot of shape data (CAC), as an estimate of the average allometric trend within groups versus size as log (CS). (a) upper molars; (b) lower molars 
TABLE 3 Upper and lower molars $p$ values of mean shape pairwise comparison between species after accounting for wear and size (allometry)

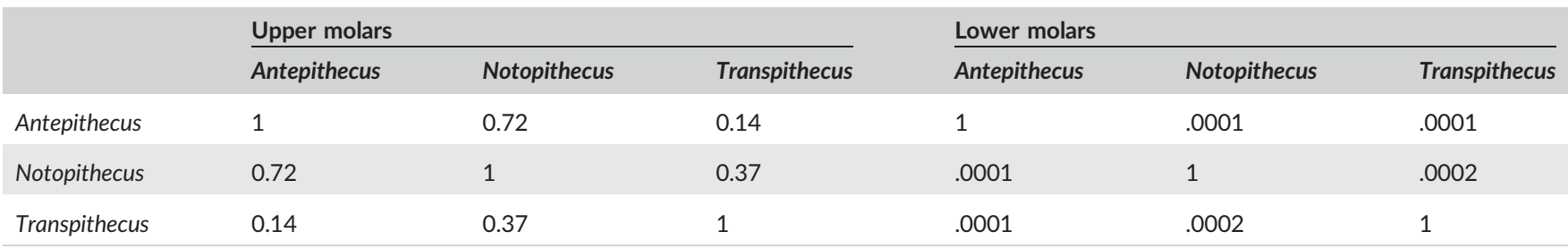

However, the fragmentary remains and/or the low number of specimens with precise taxonomic determination, usual for Eocene notoungulate fossils, have prevented in most cases the application of other methodologies to quantify these morphological changes, such as traditional or GM analyses. Fortunately, the particularly large sample of notopithecid specimens has provided an ideal model to test the "overestimation hypothesis" by means of quantitative approaches (e.g., GM) to analyze whether morphological changes in teeth (molars) are more related to ontogeny (intraspecific variation) than to interspecific differences. In this context, our present work is the first attempt using a geometry morphometric approach to study the brachydont molars of a group of Notoungulata.

The plots of mean shapes of different levels of the wear and species factor (Figures 5 and 6), allowed the observation of the morphological changes shared by molars of the notopithecids throughout their ontogeny: (1) in both upper and lower molars, width increases, relative to a decrease in length; (2) in upper molars (Figure 5a), the mesial and distal cingula fuse to the metaloph, the occlusal fossettes are erased, the parastyle and metastyle folds became less undulated, and the outline changes from trapezoidal to squared; (3) in lower molars (Figure $5 b)$, the lingual trigonid sulcus becomes shallow, as well as the mesial talonid valley, and the distal talonid valley is erased, so that the talonid presents a circular outline. In other words, characters associated to tooth shape (e.g., molar outline and size) represent a continuum along ontogeny that is strongly controlled by wearing, rather than being discrete and qualitative attributes, as traditionally considered.

In turn, when structural patterns are compared considering the mean shapes of species factor, the most noticeable morphological differences are observed in Transpithecus compared to Notopithecus and Antepithecus (Figure 6). These results agree with systematic studies that consider Transpithecus as a taxon clearly differentiable from Antepithecus and Notopithecus; in fact, only one species, T. obtentus, was originally included in this genus (Ameghino, 1901). Compared to Notopithecus and Antepithecus, Transpithecus is larger and presents upper molars with the hypocone more lingually projected than the protocone and lacking a mesial cingulum (Vera, 2012a, 2016); other less evident differences correspond to the less pointed parastyle and metastyle and more convex paracone and metacone (Figure 6a); in turn, the differences in the lower molars are more subtle and include a shorter trigonid and longer talonid (Figure 6b).

In contrast, the morphological differences between Notopithecus and Antepithecus are very subtle and a common structural pattern for both taxa is easily recognizable (Figure 6a); in fact, it is difficult to distinguish between these genera using only isolated teeth, especially upper molars. In this sense, it is worth mentioning that Antepithecus was ambiguously defined (Ameghino, 1901) and was subsequently often confused with Notopithecus in the bibliography, indeed, Simpson (1967, p. 81) included Antepithecus in his description of Notopithecus and mentioned the difficulty of distinguishing both taxa based on upper tooth morphology. Moreover, when differences in upper molar shape are analyzed taking into account the species factor only, there are no significant differences between Antepithecus and Notopithecus (Table 4). In any case, other features (not expressed in Figure 6a) beyond size distinguish Antepithecus from Notopithecus, such as upper molars with a deep lingual valley that reaches the base of the crown, and having an entoloph formed with advanced wear (Vera \& Cerdeño, 2014).

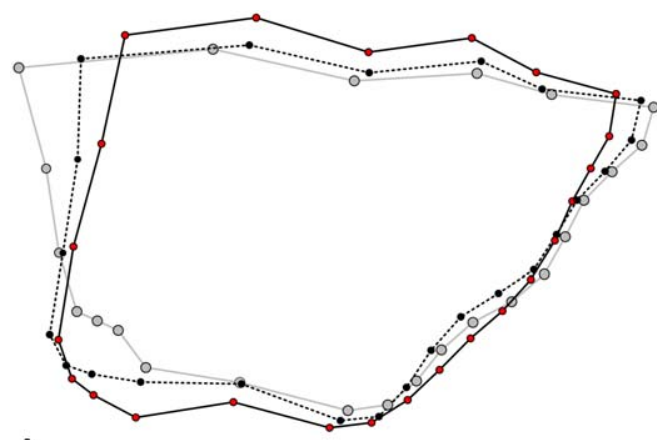

A

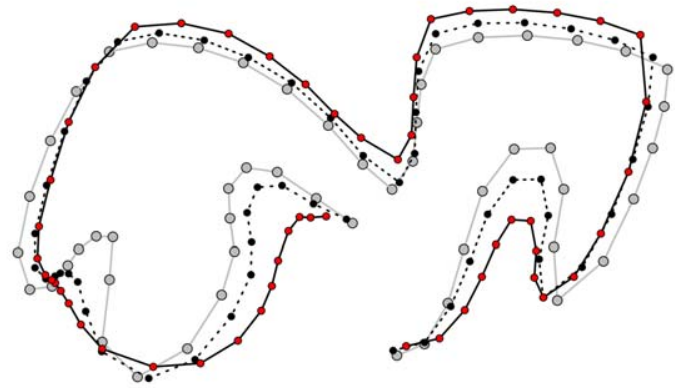

B

FIGURE 5 Comparison of (a) upper molar and (b) lower molar mean shapes for each wear stage. WS 1, little worn mean shape; WS 2 , moderate worn mean shape; WS 3 , highly worn mean shape 


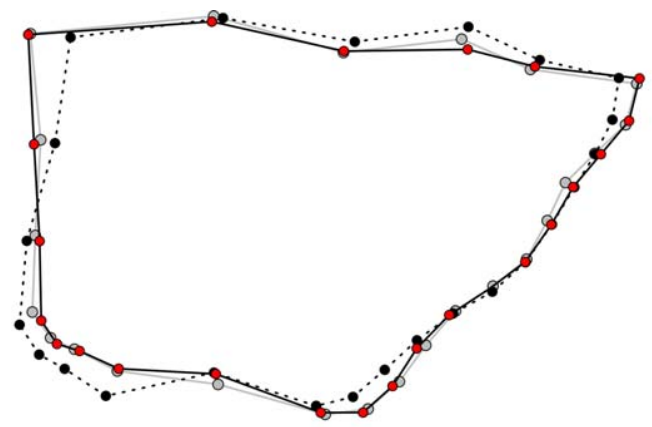

A

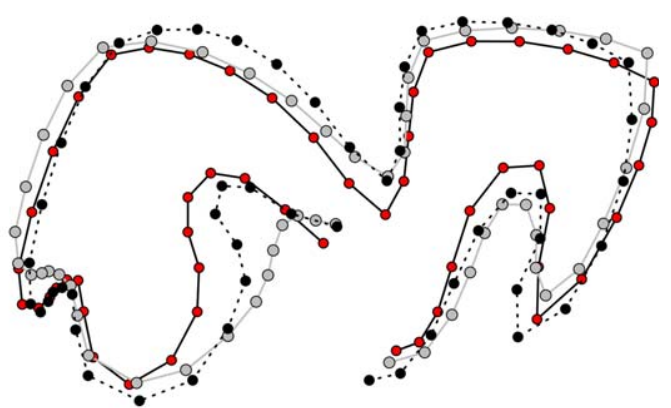

B

Notopithecus o

Transpithecus

Antepithecus

FIGURE 6 Comparison of (a) upper molar and (b) lower molar mean shapes for each species

Conversely, differences in the lower molars are more conspicuous, including a deeper lingual sulcus in the trigonid and talonid, the more inclined protolophid and longer paralophid that distinguish Antepithecus from Notopithecus (Figure 6b).

Summarizing, shape changes in the upper molars involve mainly the labial surfaces (Figures 5a and 6a), whereas those that take place in lower molars are more evident and concentrated in the lingual region (Figures $5 \mathrm{~b}$ and $6 \mathrm{~b}$ ); moreover, when only the species factor is considered in the analysis of shape differences, all three species are significantly different only with respect to their lower molars (Table 4). These contrasting results between upper and lower molars suggest that the latter are better diagnostic structures than the former at interspecific level, because their shape differences are more relevant to separate species even when wear and size effects are ignored. However, we have to put a word of caution concerning the occlusal fossettes on upper molars (a variable number of fossettes are commonly present in the little worn teeth of Paleogene notoungulates), which cannot be quantified by means of landmarks and semilandmarks in highly worn molars (with erased fossettes). This could partially explain why the species factor had a small size effect in the upper molars compared with the lower ones.

Considering the present results, the unexpected strong similarity in the upper molar pattern (Figure 6a) between Notopithecus and Antepithecus (not considering size and wear) could be supposed to have systematic relevance at first appearance. In other words, evidence based on the upper molars strongly supports the view of two different species in the same genus instead of two monospecific genera. However, our study emphasizes that such classic systematics based on upper molars only (as is typical for most Paleogene families of South American notoungulates) can yield misleading results. Surprisingly, lower tooth morphology proved to be more reliable than the upper molars for separating species within the notopithecids, as supported by a morphometric geometric approach.

\section{5 | CONCLUSIONS}

In this contribution, we applied independent geometric morphometric analyses to complex structures, namely the brachydont teeth of native South American ungulates, with consistent results.

Using notopithecids as a study-case, we demonstrated that wear is the main factor affecting molar shape, followed by the species factor (in lower molars) and allometry. This means that the main differences within each species, Notopithecus adapinus, Antepithecus brachystephanus, and Transpithecus obtentus, are mainly due to wear-related variation throughout ontogeny, supporting the hypothesis of overestimation in the number of species proposed by previous traditional systematic studies.

Moreover, the shape differences detected between the three species are more evident in lower than in upper molars, and are still distinguishable after controlling for wear and allometric size. This suggests that lower molars are better than the upper molars as diagnostic structures for interspecific differences, even when wear and size are ignored. This should be taken into account in systematic studies that are based only on the upper molars, as is frequently the case in most Paleogene families of low-crowned notoungulates.

Furthermore, this methodological approach had distinct benefits. On the one hand, the use of landmark data clearly improved the results in terms of congruence with alternative sources of evidence, such as morphological studies based on discrete characters; in addition, our

TABLE 4 Upper and lower molars $p$ values of mean shape pairwise comparison between species factor only

\begin{tabular}{|c|c|c|c|c|c|c|}
\hline & \multicolumn{3}{|l|}{ Upper molars } & \multicolumn{3}{|l|}{ Lower molars } \\
\hline & Antepithecus & Notopithecus & Transpithecus & Antepithecus & Notopithecus & Transpithecus \\
\hline Antepithecus & 1 & 0.6512 & .0116 & 1 & .0001 & .0002 \\
\hline Notopithecus & 0.6512 & 1 & .003 & .0001 & 1 & .0001 \\
\hline Transpithecus & .0116 & .003 & 1 & .0002 & .0001 & 1 \\
\hline
\end{tabular}


results are congruent with the accepted phylogeny for notopithecids and may be an important source of evidence for systematic analyses. On the other hand, landmark configurations can provide better descriptions of the morphological variability of teeth and improve the usefulness of these elements as sources of data for further phylogenetic analyses.

This study presents a new approach with potential application to other Eocene low-crowned groups, whose still unresolved systematic status is based on dental morphology, such as oldfieldthomasiids, henricosborniids, and archaeopithecids.

\section{ACKNOWLEDGMENTS}

We thank the editor of the journal and two anonymous reviewers for critical reviews of the manuscript and valuable comments. We would like to express our gratitude to the following institutions and people who provided access to the collections under their care: J. Meng, J. Galkin, and A. Gishlick (AMNH), K. Angielczyk and B. Simpson (FMNH), A. Kramarz (MACN) and S. Álvarez (FHN), M. Fornasiero and L. del Favero (MGP), M. Reguero (MLP), C. Argot (MNHN), and E. Ruigómez (MPEF). C. Morgan (MLP) revised the English. The studied sample is part of B.V.'s PhD thesis which was financially supported by the "Consejo Nacional de Investigaciones Científicas y Técnicas" (CONICET, Argentina). B.V. received funding for collection visits from the scholarship committee of the Field Museum of Natural History, USA (grant 2010-P305326); a Williams Foundation travel grant (2011); and two grants from the University of Padova, Italy (via "Proposte di finanziamento per azioni di cooperazione universitaria," 2011 and 2014). Also this work was partially funding by PICTO-UNDAV 105, Préstamo BID.

\section{AUTHOR CONTRIBUTIONS}

B. V. conceived the project and provided data sample, measurements and photographs; A. S. conducted the landmark acquisition, geometric morphometric and statistical analyses, and made figures; A. S and B.V. wrote and discussed the final manuscript.

\section{ORCID}

Alejo C. Scarano iD http://orcid.org/0000-0002-8179-3406

\section{REFERENCES}

Adams, D. C., \& Collyer, M. L. (2007). Analysis of character divergence along environmental gradients and other covariates. Evolution, 3(61), 510-515.

Adams, D. C., \& Collyer, M. L. (2009). A general framework for the analysis of phenotypic trajectories in evolutionary studies. Evolution, 5(63), 1143-1154.

Adams, D. C., \& Collyer, M. L. (2016). On the comparison of the strength of morphological integration across morphometric datasets. Evolution, 11(70), 2623-2631.

Adams, D. C., \& Otárola-Castillo, E. (2013). geomorph: An R package for the collection and analysis of geometric morphometric shape data. Methods in Ecology and Evolution, 4(4), 393-399.
Adams, D. C., Rohlf, F. J., \& Slice, D. E. (2004). Geometric morphometrics: Ten years of progress following the 'revolution'. Italian Journal of Zoology, 1(71), 5-16.

Adams, D. C., Rohlf, F. J., \& Slice, D. E. (2013). A field comes of age: Geometric morphometrics in the 21st century. Hystrix, the Italian Journal of Mammalogy, 1(24), 1-8.

Ameghino, F. (1897). Mammifères crétacés de l'Argentine. Deuxieme contribution a la connaissance de la fauna mammalogique des couches á Pyrotherium. Boletín Del Instituto Geográfico Argentino, 18, 431-521.

Ameghino, F. (1901). Notices préliminaires sur des ongulés nouveaux des terrains crétacés de Patagonie. Boletín De La Academia Nacional De Ciencias De Córdoba, 16, 349-426.

Ameghino, F. (1903). Nuevas especies de mamíferos cretáceos y terciarios de la República Argentina. Anales De La Sociedad Científica Argentina, 56, 193-208.

Ameghino, F. (1904). Recherches de morphologie phylogénétique sur les molaires supérieures des ongulés. Anales del Museo Nacional de Buenos Aires, 3, 1-541.

Ameghino, F. (1906). Les formations sédimentaires du Crétacé Supérieur et du Tertiaire de Patagonie avec un parallèle entre leurs faunes mammalogiques et celles de l'ancien continent. Anales Del Museo Nacional De Buenos Aires, 15, 1-568.

Anderson, M. J. (2001). A new method for non-parametric multivariate analysis of variance. Austral Ecology, 1(26), 32-46.

Bernal, V. (2007). Size and shape analysis of human molars: Comparing traditional and geometric morphometric techniques. HOMO-Journal of Comparative Human Biology, 4(58), 279-296.

Berns, C. M., \& Adams, D. C. (2013). Becoming different but staying alike: Patterns of sexual size and shape dimorphism in bills of hummingbirds. Evolutionary Biology, 40, 246-260.

Billet, G., De Muizon, C., \& Quispe, B. M. (2008). Late Oligocene mesotheriids (Mammalia, Notoungulata) from Salla and Lacayani (Bolivia): Implications for basal mesotheriid phylogeny and distribution. Zoological Journal of the Linnean Society, 1(152), 153-200.

Billet, G., Patterson, B., \& De Muizon, C. (2009). Craniodental anatomy of late Oligocene archaeohyracids (Notoungulata, Mammalia) from Bolivia and Argentina and new phylogenetic hypotheses. Zoological Journal of the Linnean Society, 155, 458-509.

Bookstein, F. L. (1996). Applying landmark methods to biological outline data. In K. V. Mardia, C. A. Gill, \& I. L. Dryden (Eds.), Image fusion and shape variability. (pp. 79-87). Leeds: University of Leeds Press.

Bookstein, F. L. (1997). Landmark methods for forms without landmarks: Localizing group differences in outline shape. Medical Image Analysis, 1, 225-243.

Bookstein, F. L., Streissguth, A. P., Sampson, P. D., Connor, P. D., \& Barr, H. M. (2002). Corpus callosum shape and neuropsychological deficits in adult males with heavy fetal alcohol exposure. Neuroimage, 15, 233-251.

Butler, P. M. (1983). Evolution and mammalian dental morphology. Journal De Biologie Buccale, 11(4), 285-302.

Catalano, S. A., Ercoli, M. D., \& Prevosti, F. J. (2014). The more, the better The use of multiple landmark configurations to solve the phylogenetic relationships in musteloids. Systematic Biology, 64(2), 294-306.

Cerdeño, E., Chiesa, J., \& Ojeda, G. (2008). Presence of Oxyodontherium (Macraucheniidae, Litopterna) in the Río Quinto Formation, San Luis (Argentina). Journal of South American Earth Sciences, 25, 217-226.

Cerdeño, E., Montalvo, C. I., \& Sostillo, R. (2017). Deciduous dentition and eruption pattern in late Miocene Pachyrukhinae (Hegetotheriidae, Notoungulata) from La Pampa Province, Argentina. Historical Biology, 3(29), 359-375. 
Cerdeño, E., Reguero, M., \& Vera, B. (2010). Deseadan Archaeohyracidae (Notoungulata) from Quebrada Fiera (Mendoza, Argentina) in the paleobiogeographic context of the South American late Oligocene. Journal of Paleontology, 6(84), 1177-1187.

Claude, J. (2008). Morphometrics with R. Berlin, Germany: Springer Science \& Business Media.

Claude, J. (2013). Log-shape ratios, Procrustes superimposition, elliptic Fourier analysis: Three worked examples in R. Hystrix, the Italian Journal of Mammalogy, 1(24), 94-102.

Collyer, M. L., \& Adams, D. C. (2007). Analysis of two-state multivariate phenotypic change in ecological studies. Ecology, 3(88), 683-692.

Collyer, M. L., \& Adams, D. C. (2013). Phenotypic trajectory analysis: Comparison of shape change patterns in evolution and ecology. Hystrix, 1(24), 75-83.

Collyer, M. L., Sekora, D. J., \& Adams, D. C. (2015). A method for analysis of phenotypic change for phenotypes described by highdimensional data. Heredity (Edinb), 4(115), 357-365.

Collyer, M. L., Stockwell, C. A., Adams, D. C., \& Reiser, M. H. (2007). Phenotypic plasticity and contemporary evolution in introduced populations: Evidence from translocated populations of white sands pupfish (Cyrpinodon tularosa). Ecological Research, 6(22), 902-910.

Croft, D. A., Reguero, M., Bond, M., Wyss, A. R., \& Flynn, J. J. (2003). Large Archaeohyracids (Typotheria, Notoungulata) from Central Chile and Patagonia, including a revision of Archaeotypotherium. Fieldiana, Geology Series, 49, 1-38.

Damuth, J., \& Janis, C. M. (2011). On the relationship between hypsodonty and feeding ecology in ungulate mammals, and its utility in palaeoecology. Biological Reviews, 86, 733-758.

Dryden, I. L., \& Mardia, K. V. (1998). Statistical shape analysis (1st. ed.). Chichester: Wiley.

Ercoli, M. D., Candela, A. M., Rasia, L. L., \& Ramírez, M. A. (2017). Dental shape variation of Neogene Pachyrukhinae (Mammalia, Notoungulata, Hegetotheriidae): Systematics and evolutionary implications for the late Miocene Paedotherium species. Journal of Systematic Palaeontology. https://doi.org/10.1080/14772019.2017.1366956

Erickson, K. L. (2014). Prairie grass phytolith hardness and the evolution of ungulate hypsodonty. Historical Biology, 6(26), 737-744.

Fortelius, M. (1985). Ungulate cheek teeth: Developmental, functional, and evolutionary interrelations. Acta Zoologica Fennica, 180, 1-76.

Fortelius, M., \& Solounias, N. (2000). Functional characterization of ungulate molars using the abrasion-attrition wear gradient: $\mathrm{A}$ new method for reconstructing paleodiets. American Museum Novitates, 3301(3301), 1-36.

Fox, C. L., Juan, J., \& Albert, R. M. (1996). Phytolith analysis on dental calculus, enamel surface, and burial soil: Information about diet and paleoenvironment. American Journal of Physical Anthropology, 1(101), 101-113.

Francis, J. (2013). Análisis de algunos factores de confusiyn en la sistemática gen h̆rica de los Mesotheriinae (Notoungulata, Typotheria). Ameghiniana, 2(2), 29-36.

Gunz, P., \& Mitteroecker, P. (2013). Semilandmarks: A method for quantifying curves and surfaces. Hystrix, the Italian Journal of Mammalogy, 1(24), 103-109.

Janis, C. M. (1995). Correlations between craniodental morphology and feeding behavior in ungulates: Reciprocal illumination between living and fossil taxa. In J. Thomason (Ed.), Functional morphology in vertebrate paleontology (pp. 76-98). Cambridge, England: Cambridge University Press.

Janis, C. M., \& Fortelius, M. (1988). On the means whereby mammals achieve increased functional durability of their dentitions, with special reference to limiting factors. Biological Reviews of the Cambridge Philosophical Society, 2(63), 197-230.

Kelly, C. D., Folinsbee, K. E., Adams, D. C., \& Jennions, M. D. (2013). Intraspecific sexual size and shape dimorphism in an australian freshwater fish differs with respect to a biogeographic barrier and latitude. Evolutionary Biology, 40, 408-419.

Klingenberg, C. P. (2016). Size, shape, and form: Concepts of allometry in geometric morphometrics. Development Genes and Evolution, 3 (226), 113-137.

Kubo, M. O., \& Yamada, E. (2014). The inter-relationship between dietary and environmental properties and tooth wear: Comparisons of mesowear, molar wear rate, and hypsodonty index of extant sika deer populations. PLoS One, 3(9), 1-12.

Lucas, P. W., Constantino, P., Wood, B., \& Lawn, B. (2008). Dental enamel as a dietary indicator in mammals. Bioessays, 4(30), 374-385.

Lucas, P. W., van Casteren, A., Al-Fadhalah, K., Almusallam, A. S., Henry, A. G., Michael, S., ... Atkins, A. G. (2014). The role of dust, grit and phytoliths in tooth wear. Annales Zoologici Fennici, 1-2(51), 143-152.

MacFadden, B. J. (1997). Origin and evolution of the grazing guild in New World terrestrial mammals. Trends in Ecology \& Evolution, 12(5), 182-187.

Madden, R. D. (1997). A new toxodontid notoungulate. In R. F. Kay, R. H. Madden, R. F. Cifelli, \& J. J. Flynn (Eds.), Vertebrate paleontology in the neotropics: The miocene fauna of la venta, Colombia (pp. 335-354). Washington, DC: Smithsonian Institution Press.

Massey, F. P., \& Hartley, S. E. (2006). Experimental demonstration of the antiherbivore effects of silica in grasses: Impacts on foliage digestibility and vole growth rates. Proceedings of the Royal Society of London B: Biological Sciences, 1599(273), 2299-2304.

McGuire, J. (2010). Geometric morphometrics of vole (Microtus californicus) dentition as a new paleoclimate proxy: Shape change along geographic and climatic clines. Quaternary International, 212(2), 198-205.

Mitteroecker, P., Gunz, P., Bernhard, M., Schaefer, K., \& Bookstein, F. L. (2004). Comparison of cranial ontogenetic trajectories among great apes and humans. Journal of Human Evolution, 6(46), 679-697.

M'kirera, F., \& Ungar, P. S. (2003). Occlusal relief changes with molar wear in Pan troglodytes troglodytes and Gorilla gorilla gorilla. American Journal of Primatology, 2(60), 31-41.

Mones, A. (1982). An equivocal nomenclature: What means hypsodonty? Palaontologische Zeitschrift, 1-2, 107-111.

Polly, P. D., Stayton, C. T., Dumont, E. R., Pierce, S. E., Rayfield, E. J., \& Angielczyk, K. D. (2016). Combining geometric morphometrics and finite element analysis with evolutionary modeling: Towards a synthesis. Journal of Vertebrate Paleontology, 36, e1111225.

R Development Core Team. (2013). R: A language and environment for statistical computing. Vienna, Austria: R Foundation for Statistical Computing. ISBN 3-900051-07-0. Retrieved from http://www.Rproject.org

Rensberger, J. M. (1973). An occlusal model for mastication and dental wear in herbivorous mammals. Journal of Paleontology, 47, 515-528.

Rohlf, F. J. (1999). Shape statistics: Procrustes superimpositions and tangent spaces. Journal of Classification, 2(16), 197-223.

Rohlf, F. J., \& Marcus, L. F. (1993). A revolution in morphometrics. Trends in Ecology and Evolution, 4(8), 129-132.

Rohlf, F. J., \& Slice, D. (1990). Extensions of the procrustes method for the optimal superimposition of landmarks. Systematic Zoology, 1(39), 40-59.

Rohlf, R. J. (2008). TPSDIG, Version 2.12. Stony Brook, NY: Department of Ecology and Evolution, State University of New York. Retrieved from http://life.bio.sunysb.edu/morph/ 
Sanson, G. D., Kerr, S. A., \& Gross, K. A. (2007). Do silica phytoliths really wear mammalian teeth? Journal of Archaeological Science, 4(34), 526-531.

Simpson, G. G. (1945). The principles of classification and a classification of mammals. Bulletin of the American Museum of Natural History, 85, $1-350$.

Simpson, G. G. (1953). Trends and orientation. In The major features of evolution (pp. 245-280). New York City, New York: Columbia University Press.

Simpson, G. G. (1967). The beginning of the age of mammals in South America. Part 2, Systematics: Notoungulata, concluded (Typotheria, Hegetotheria, Toxodonta, Notoungulata incertae sedis), Astrapotheria, Trigonostylopoidea, Pyrotheria, Xenungulata, Mammalia incertae sedis. Bulletin of the AMNH, v. 137.

Stromberg, C. A. E. (2006). Evolution of hypsodonty in equids: Testing a hypothesis of adaptation. Paleobiology, 2(32), 236-258.

Ungar, P. S. (2009). Tooth form and function: Insights into adaptation through the analysis of dental microwear. In T. Koppe, G. Meyer, \& K. W. Alt (Eds.), Comparative dental morphology (pp. 38-43. Basel, Switzerland: Karger Publishers.

Ungar, P. S. (2015). Mammalian dental function and wear: A review. Biosurface and Biotribology, 1(1), 25-41.

Vera, B. (2012a). Revisión del género Transpithecus Ameghino, 1901 (Notoungulata, Interatheriidae) del Eoceno medio de Patagonia, Argentina. Ameghiniana, 1(49), 60-74.

Vera, B. (2012b). Postcranial morphology of Notopithecus Ameghino, 1897 (Notoungulata, Interatheriidae) from the middle Eocene of Patagonia, Argentina. Journal of Vertebrate Paleontology, 5(32), 11351148.
Vera, B. (2013). Sistemática, filogenia y paleoecologia de los Notopithecinae (Interatheriidae, Notoungulata) del Paleygeno de Argentina. (2013-02-18)

Vera, B. (2016). Phylogenetic revision of the South American notopithecines (Mammalia: Notoungulata). Journal of Systematic Palaeontology, 6(14), 461-480.

Vera, B. (2017). Patagonian Eocene Archaeopithecidae Ameghino, 1897 (Notoungulata): Systematic revision, phylogeny and biostratigraphy. Journal of Paleontology. https://doi.org/10.1017/jpa.2017.53

Vera, B., \& Cerdeño, E. (2014). New insights on Antepithecus brachystephanus Ameghino, 1901 and dental eruption sequence in 'notopithecines'(Mammalia, Notoungulata) from the Eocene of Patagonia, Argentina. Geobios, 47, 165-181.

Zelditch, M. L., Swiderski, D. L., \& Sheets, H. D. (2012). Geometric morphometrics for biologists: A primer (2nd ed.). Cambridge, MA: Academic Press.

\section{SUPPORTING INFORMATION}

Additional Supporting Information may be found online in the supporting information tab for this article.

How to cite this article: Scarano AC, Vera B. Geometric morphometric analysis as a proxy to evaluate age-related change in molar shape variation of low-crowned Notoungulata (Mammalia). Journal of Morphology. 2018;279:216-227. https://doi.org/ 10.1002/jmor.20766 